\title{
Oxidative Stress and Neuronal Injury After Cannabis and Ketamine Administration
}

\author{
OMAR M.E. ABDEL-SALAM ${ }^{1}$, EMAN R. YOUNESS ${ }^{2}$, AMANY AMEEN SLEEM $^{3}$. ENAYAT A. \\ OMARA $^{4}$ \\ ${ }^{1}$ Department of Toxicology and Narcotics, National Research Centre, Tahrir Street, Cairo, EGYPT \\ ${ }^{2}$ Medical Biochemistry, National Research Centre, Tahrir Street, Cairo, EGYPT \\ ${ }^{3}$ Pharmacology, National Research Centre, Tahrir Street, Cairo, EGYPT \\ ${ }^{4}$ Pathology, National Research Centre, Tahrir Street, Cairo, EGYPT
}

\begin{abstract}
Cannabis sativa and ketamine are common substances of abuse causing psychotic events and neurodegeneration. In this study, the effect of pretreatment with Cannabis sativa extract on oxidative stress, inflammatory mediators and brain damage induced by ketamine was investigated. Rats were treated with subcutaneous injections of cannabis extract $(10,20,30 \mathrm{or} 40 \mathrm{mg} / \mathrm{kg}$; expressed as $\Delta 9$-THC content) daily for three weeks and then in combination with ketamine $(15 \mathrm{mg} / \mathrm{kg}$, intraperitoneally) for another 5 days. Rats were tested for biochemical markers of oxidative stress including malondialdehyde (MDA) reduced glutathione (GSH), and nitric oxide (NO) concentrations in brain. Paraoxonase-1 (PON-1) activity, and levels of the proinflammatory cytokines, interleukin-1 $\beta$ (IL-1 $\beta$ ), and tumour necrosis factor- $\alpha$ (TNF- $\alpha)$ in brain were also determined at the end of treatment period. Results indicated that compared with the saline control group, ketamine induced significant elevation in brain MDA and NO, which was accompanied by depletion of GSH and inhibition of PON-1 activity. Ketamine also significantly increased brain IL-1 $\beta$ and TNF- $\alpha$ and induced neuronal necrosis, apoptosis and vacuolation. Cannabis sativa $(20-40 \mathrm{mg} / \mathrm{kg})$ pretreated rats showed lower levels of oxidative stress and inflammation and doses of 30 or $40 \mathrm{mg} / \mathrm{kg}$ slightly reduced neuronal apoptosis and necrosis. These findings suggest that cannabis constituents do not enhance the neurotoxic effects of ketamine and might partly counteract the effects of ketamine-induced NMDA antagonism by reducing the release of free radicals and inflammatory mediators in brain.
\end{abstract}

Key-Words: - Cannabis sativa, ketamine; oxidative stress, neuroinflammation, neurodegeneration

Received: March 30, 2021. Revised: July 15, 2021. Accepted: August 6, 2021. Published: August 14, 2021.

\section{Introduction}

Cannabis sativa is the most widely abused substance worldwide. It is commonly available forms are marijuana, from the plant leaves and flowers or hashish which is the compressed resin and flowers [1]. The popularity of Cannabis sativa as a recreational drug is reflected in the fact that the UN office for drug and crime estimated that in 2018, cannabis was used by $\sim 192$ million adults globally [2]. Cannabis is usually smoked in the form of cigarettes or water pipe. Users experience the so called "high"; euphoria or, relaxation and perceptual alterations [1]. The principal constituent responsible for the psychotropic effects of cannabis is delta-9tetrahydrocannabinol [ $\left.\Delta^{9}-\mathrm{THC}\right]$ [3]. The effects of cannabis are the result of complex interaction between more than 100 different cannabinoid compounds that might have an antagonistic or synergistic actions to that of $\Delta^{9}$-THC [4]. These cannabinoids and their endogenous legends or endocannabinoids exert their effects by acting on two G-protein coupled receptors; CB1 expressed in brain and CB2 expressed predominantly on immune cells in the periphery [5]. In this context, $\triangle 9-\mathrm{THC}$, acts as a partial agonist at CB1 receptors [6]. Cannabis also contains many other compounds including terpenes, carbohydrates, fatty acids and their esters, phytosterols, and phenolic compounds [4]. Studies suggested an association between heavy and regular cannabis use and the development of psychosis [7]. Chronic heavy users also showed brain structural alterations [8] while animals studies demonstrated neurotoxic effects for cannabis in high doses $[9,10]$.

Ketamine, a phencyclidine derivative, is a dissociative anesthetic with psychedelic and psychotic properties. The drug is a competitive antagonist at the $N$-methyl-D-aspartate (NMDA) 
subtype of glutamate receptor subtype on GABAergic interneurons, resulting in increased release of glutamate in the prefrontal cortex [11]. It is used at subanesthetic doses for alleviating pain or inducing mild sedation in humans $[12,13]$ and as an adjunct to morphine in the management of moderate to severe acute pain [14]. Because of its psychedelic properties, ketamine is a drug of abuse, causing dissociation, hallucinatory experiences and altered sensory perceptions [15]. It is also capable of inducing psychotic-like symptoms both in humans and rodents and therefore is widely used as an experimental model of schizophrenia $[15,16]$. The widespread use of ketamine as a recreational drug in recent years has raised concerns as regards possible health consequences. Frequent, daily use is associated with neuro-cognitive impairment, deficits in working and episodic memory and frontal lobe white matter abnormalities [11]. In rodents, ketamine induces neuronal degeneration both in developing [17] and adult [18] brain.

Cannabis is considered a gateway to other drugs of abuse and so users of cannabis will also use other psychotropic drugs making the combined abuse of cannabis and ketamine a likely possibility. Whether this will result in increased neurotoxicity is not known. The aim of this study was therefore to investigate whether the prior administration of Cannabis sativa is able to modulate the neurodegeneration induced by ketamine.

\section{Materials and methods}

\subsection{Animals}

Sprague-Dawley rats of both sexes, weighing 160 $170 \mathrm{~g}$, from the animal house colony of the National Research Centre (NRC) were used in the study and fed with standard laboratory chow and water ad libitum. Animal procedures were performed in accordance to the Institutional Ethics Committee and in accordance with the recommendations for the proper care and use of laboratory animals (Directive 2010/63/EU revising Directive 86/609/EEC on the protection of animals used for scientific purposes).

\subsection{Drugs and Chemicals}

Cannabis sativa and ketamine were obtained from the Ministry of Justice. Other chemical and reagents were obtained from Sigma (St. Louis, USA). Ketamine was dissolved in saline to obtain the necessary doses.

\subsubsection{Preparation of the cannabis extract}

The extract of Cannabis sativa L. was obtained from the dried flowering tops and leaves of the plant by chloroform treatment according to Turner and Mahlberg [19] with modification. In brief, $10 \mathrm{~g}$ of dried cannabis was ground with a mortar and pestle. Cannabinoids are enzymatically biosynthesised in the plant as their corresponding carboxylic acid forms. Neutral cannabinoids are formed via decarboxylation of the acidic cannabinoids during exposure to heat [19]. Decarboxylation of the plant material was achieved by placing the sample in a glass test tube $(30 \mathrm{~mL})$ and covering it with aluminum foil. The test tubes were placed in boiling water bath $\left(100^{\circ} \mathrm{C}\right)$ for $2 \mathrm{~h}$. Ten milliliters of analytical grade chloroform was added and allowed to react overnight. The dried cannabis was extracted three times and fractions were combined, filtered over filter paper and collected in $100 \mathrm{~mL}$ volumetric flask. The filtrate was evaporated under a gentle stream of nitrogen (on ice and protected from light and stored at $4{ }^{\circ} \mathrm{C}$ and protected from light in an aluminum-covered container, which provided the dry extract as residue. For injection, the residue was resuspended in $2 \mathrm{~mL}$ of $96 \%$ ethanol and the total volume in the volumetric flask increased to $100 \mathrm{~mL}$ by adding distilled water. The extract was injected subcutaneously at doses of $5,10,30$ and $40 \mathrm{mg} / \mathrm{kg}$ (expressed as $\Delta^{9}$-THC). Tetrahydrocannabinol (THC) content was quantified using "GC mass spec". The dry extract contained $10 \%$ of the $\Delta^{9}$-THC.

\subsection{Experimental design}

Different groups of rats $(\mathrm{n}=6$ each) were used. Rats were randomly assigned to the following treatment groups:

Group 1 received the vehicle $(0.2 \mathrm{ml}$ saline $)$ daily. Groups 2, 3, and 4 received cannabis $(5,10,30$ and $40 \mathrm{mg} / \mathrm{kg}$ : equivalent to the active constituent $\Delta^{9}$ tetrahydrocannabinol) subcutaneously daily for three weeks and then together with i.p. ketamine (15 $\mathrm{mg} / \mathrm{kg}$ ) for another 5 days.

Group 5 received saline subcutaneously daily for three weeks and then together with i.p. ketamine (15 $\mathrm{mg} / \mathrm{kg}$ ) for another 5 days.

Rats were subsequently euthanized by decapitation. The whole brain of each rat was rapidly removed out and snap-frozen in liquid nitrogen. Brain tissue samples were stored at $-80{ }^{\circ} \mathrm{C}$ until further processing. Frozen samples were thawed and homogenized in a glass tube with a Teflon dounce pestle in ice-cold phosphate buffer solution $(50 \mathrm{mM}$ Tris-HCl, $\mathrm{pH}$ 7.4) and sonicated. Homogenized samples were then centrifuged at $9000 \mathrm{~g}$ for $5 \mathrm{~min}$ at 
$4{ }^{\circ} \mathrm{C}$. The supernatant was stored at $-80{ }^{\circ} \mathrm{C}$ until further analysis. Biochemical markers of oxidative stress including GSH, MDA, nitric oxide, paraoxonase- 1 , and the proinflammatory cytokines IL-1 $\beta$, TNF- $\alpha$ in the brain were estimated at end of the treatment period. The histopathological study was carried out on separate groups of rats $(n=4$ per group).

\subsection{Biochemical assessments}

\subsubsection{Lipid peroxidation}

Lipid peroxidation was measured by determination of malondialdehyde (MDA) in the brain homogenates [20]. Thiobarbituric acid reactive substances (TBAS) react with thiobarbituric acid forming TBA-MDA adduct and the absorbance is read at $532 \mathrm{~nm}$ using spectrophotometer.

\subsubsection{Reduced glutathione}

Reduced glutathione (GSH) was determined in homogenates according to Ellman [21]. Briefly, DTNB (5,5'-dithiobis (2-nitrobenzoic acid) or Ellman's reagent is reduced by the free sulfhydryl group on GSH molecule to generate 5-thio-2nitrobenzoic acid which has yellow color and can be determined by reading absorbance at $412 \mathrm{~nm}$.

\subsubsection{Nitric oxide}

Nitric oxide, estimated as nitrate/nitrite was determined using the Griess reaction. In this assay nitrate is converted to nitrite via nitrate reductase. Griess reagent then acts to convert nitrite to a deep purple azo compound that can be determined using spectrophotometer at $540 \mathrm{~nm}$ [22].

\subsubsection{Paraoxonase-1}

The arylesterase activity of PON-1 was determined by a colorimetric method using phenyl acetate as a substrate. In this assay, PON-1 catalyzes the cleavage of phenyl acetate resulting in phenol formation. The rate of formation of phenol was measured by monitoring the increase in absorbance at $270 \mathrm{~nm}$ at $25^{\circ} \mathrm{C}$. The working mix consisted of $20 \mathrm{mM}$ Tris $/ \mathrm{HCl}$ buffer, $\mathrm{pH} 8.0$, containing $1 \mathrm{mM} \mathrm{CaCl} 2$ and $4 \mathrm{mM}$ phenyl acetate as the substrate. Samples diluted 1:3 in buffer were added to the above mix and the changes in absorbance were recorded following a 20 $\mathrm{s}$ lag time. One unit of arylesterase activity is equal to $1 \mu$ mole of phenol formed per min. The PON-1 activity is expressed in $\mathrm{kU} / \mathrm{l}$, based on the extinction coefficient of phenol of $1310 \mathrm{M}^{-1} \mathrm{~cm}^{-1}$. Blank samples containing water were used to correct for the spontaneous hydrolysis of phenyl acetate [23].

\subsubsection{Interleukin-1 $\beta$}

IL-1 $\beta$ was measured in tissue supernatants using commercially available IL-1 $\beta$ ELISA kit (KOMA BIOTECH Inc.) according to manufacture instructions. The kit uses a double antibody sandwich enzyme linked immunosorbent assay to measure the level of IL-1 $\beta$.

\subsubsection{Tumour necrosis factor- $\alpha$}

TNF- $\alpha$ levels in the supernatants were measured using a double-antibody sandwich enzyme-linked immunosorbent assay (ELISA) kit supplied by Thermofischer Scientific Co, USA according to the manufacture instructions.

\subsection{Histopathological assessments}

The brains from the control and experimental groups were fixed with $10 \%$ formalin and embedded in paraffin wax and cut into longitudinal sections of 5 $\mu \mathrm{m}$ thickness. The sections were stained with Hemotoxylin and Eosin (Hx \& E) dye for histopathological observations.

\subsection{Statistical analysis}

All data were expressed as the mean \pm SEM. Data were analyzed by one-way analysis of variance (ANOVA) followed by followed by Tukey's multiple comparisons test. GraphPad Prism 6 for Windows (GraphPad Prism Software Inc., San Diego, CA, USA) was used. Statistical significance was considered at a probability value of less than 0.05 .

\section{Results}

\subsection{Oxidative stress}

\subsubsection{Lipid peroxidation}

In ketamine only-treated rats, MDA contents of cerebral cortex and striatum increased significantly by $56.3 \%$ and $45.0 \%$, respectively, from saline control values $17.68 \pm 0.75$ and $17.14 \pm 0.25$ to 27.63 \pm 1.8 and $24.84 \pm 0.40 \mathrm{nmol} / \mathrm{g}$.tissue. The cannabis/ketamine treated groups exhibited significantly lower MDA values compared with the ketamine only group. Cannabis given at 20,30 and $40 \mathrm{mg} / \mathrm{kg}$ decreased MDA levels in cerebral cortex $15.5,23.6$ and $26.9 \%$, respectively, from control levels of $27.63 \pm 1.8$ to $23.36 \pm 0.64,21.1 \pm 0.73$ and $20.21 \pm 0.58 \mathrm{nmol} / \mathrm{g}$.tissue. Meanwhile, MDA levels in striatum decreased by 12.3 and $22.1 \%$ by cannabis at 30 or $40 \mathrm{mg} / \mathrm{kg}$, respectively $(21.78 \pm 0.48$ and $19.35 \pm 0.60$ vs. $24.84 \pm 0.40 \mathrm{nmol} / \mathrm{g}$.tissue) (Fig. 1).

\subsubsection{Reduced glutathione}

Ketamine significantly decreased GSH levels in cerebral cortex and striatum by $58.4 \%$ and $43.1 \%$ 
from saline control levels of $3.94 \pm 0.08$ and $3.69 \pm$ 0.1 to $1.64 \pm 0.07$ and $2.10 \pm 0.11 \mu \mathrm{mol} / \mathrm{g}$.tissue. In rats treated with 30 and $40 \mathrm{mg} / \mathrm{kg}$ cannabis, GSH levels were significantly increased by $45.7 \%$ and $74.4 \%$ in cerebral cortex $(2.39 \pm 0.15$ and $2.86 \pm 0.21$ vs. $1.64 \pm 0.07 \mu \mathrm{mol} / \mathrm{g}$.tissue) and by $33.8 \%$ and $54.8 \%$ in striatum $(2.81 \pm 0.13$ and $3.25 \pm 0.17$ vs. $2.10 \pm 0.11 \mu \mathrm{mol} /$ g.tissue), respectively(Fig. 1).

\subsubsection{Nitric oxide}

Compared with the saline control group, ketamine induced significant decrease in nitric oxide levels in cerebral cortex and striatum by $21.0 \%$ and $23.9 \%$, respectively, from saline values $19.88 \pm 0.64$ and $18.78 \pm 0.47$ to $15.72 \pm 0.43$ and $14.30 \pm 0.12$ $\mu \mathrm{mol} / \mathrm{g}$.tissue. Cannabis given at 30 or $40 \mathrm{mg} / \mathrm{kg}$ resulted in further decrease in nitric oxide levels in cerebral cortex by $16.1 \%$ and $23 \%$ and in striatum by $9.6 \%$ and $15.4 \%$, respectively (Fig. 1).

\subsection{Paraoxonase-1}

In the ketamine only treated group, $\mathrm{PON}-1$ activity showed significant decrease by $38.9 \%$ in cortex $(8.1 \pm$ 0.27 vs. $13.25 \pm 0.24 \mathrm{kU} / 1)$ and by $43.7 \%$ striatum $(6.97 \pm 0.19$ vs. $12.38 \pm 0.39)$ compared with the saline control group. In the cannabis/ketamine groups, PON-1 activity was significantly increased in cerebral cortex by $36.3 \%, 43.3 \%, 55.9 \%$ by cannabis given at 20,30 or $40 \mathrm{mg} / \mathrm{kg}(11.04 \pm 0.35,11.61 \pm$ $0.24,12.63 \pm 0.32$ vs. $8.1 \pm 0.27 \mathrm{kU} / 1)$. Significantly increased PON-1 activity by $26.7 \%$ and $45.0 \%$ was also observed in the striatum of rats treated with cannabis at 30 or $40 \mathrm{mg} / \mathrm{kg}(8.83 \pm 0.38,10.1 \pm 0.17$ vs. $6.97 \pm 0.19 \mathrm{kU} / \mathrm{l})$ (Fig. 1).

\subsection{Interleukin-1 $\beta$}

A significant increase in IL-1 $\beta$ level in cerebral cortex was observed in rats treated with only ketamine compared with their saline controls (157.3 \pm 4.1 vs. $76.1 \pm 2.2 \mathrm{pg} / \mathrm{ml})$. On the other hand, rats pretreated with cannabis at $40 \mathrm{mg} / \mathrm{kg}$ showed significantly lower IL- $1 \beta$ level by $14.0 \%$ compared with the ketamine control group (135.2 \pm 6.9 vs. 157.3 $\pm 4.1 \mathrm{pg} / \mathrm{ml}$ ) (Fig. 2).

\subsection{Tumour necrosis factor- $\alpha$}

The level of TNF- $\alpha$ in cerebral cortex was significantly increased in the ketamine only group compared with the saline control (102 \pm 3.1 vs. 40.1 $\pm 2.0 \mathrm{pg} / \mathrm{ml}$ ). Cannabis given at 30 or $40 \mathrm{mg} / \mathrm{kg}$ prior to ketamine significantly decreased the raised TNF- $\alpha$ by 19.2 and $30.5 \%$, respectively $(82.4 \pm 2.4,70.9$ \pm 1.8 vs. $102.0 \pm 3.1 \mathrm{pg} / \mathrm{ml}$ ) (Fig. 2).
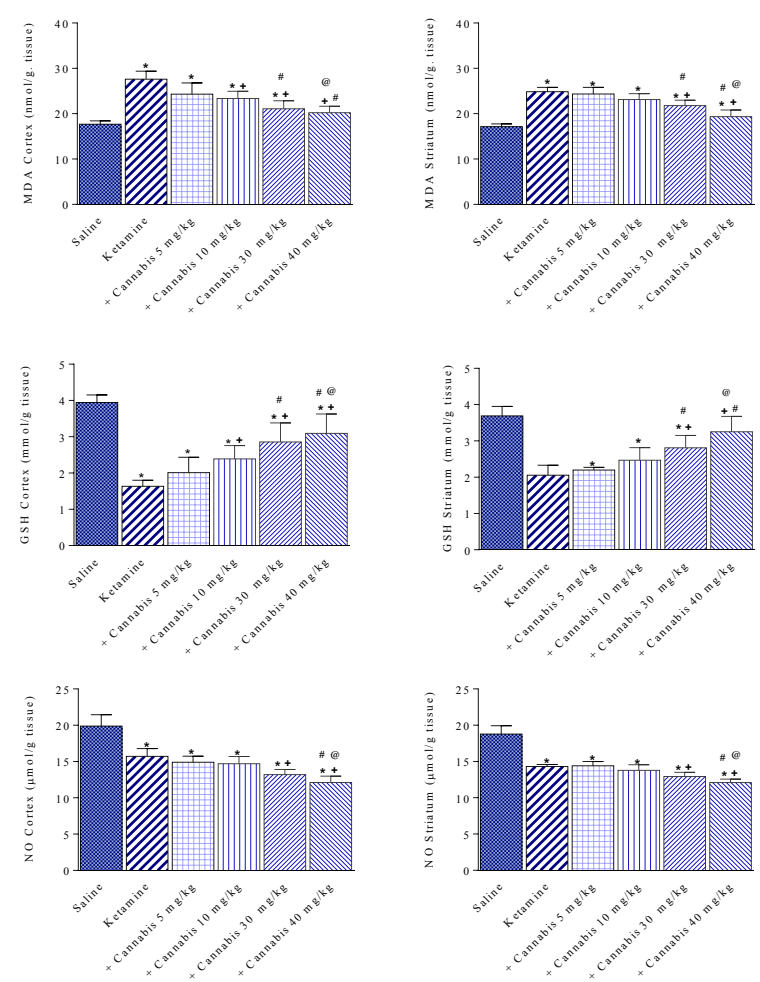

Fig. 1. Effect of ketamine or cannabis/ ketamine on brain malondialdehyde (MDA), reduced glutathione (GSH) and nitric oxide (NO). Rats received s.c. injections of cannabis extract (10, 20,30 or $40 \mathrm{mg} / \mathrm{kg}$; expressed as $\Delta^{9}$-THC content) daily for three weeks and then in combination with ketamine $(15 \mathrm{mg} / \mathrm{kg}$, i.p.) for another 5 days. ${ }^{*}$ : $\mathrm{P}<0.05$ vs. saline control. +: $\mathrm{P}<0.05$ vs. ketamine only group. \#: $\mathrm{P}<0.05$ vs. ketamine/cannabis $5 \mathrm{mg} / \mathrm{kg}$ treated group. @: $\mathrm{P}<0.05$ vs. ketamine/cannabis $10 \mathrm{mg} / \mathrm{kg}$ treated group.
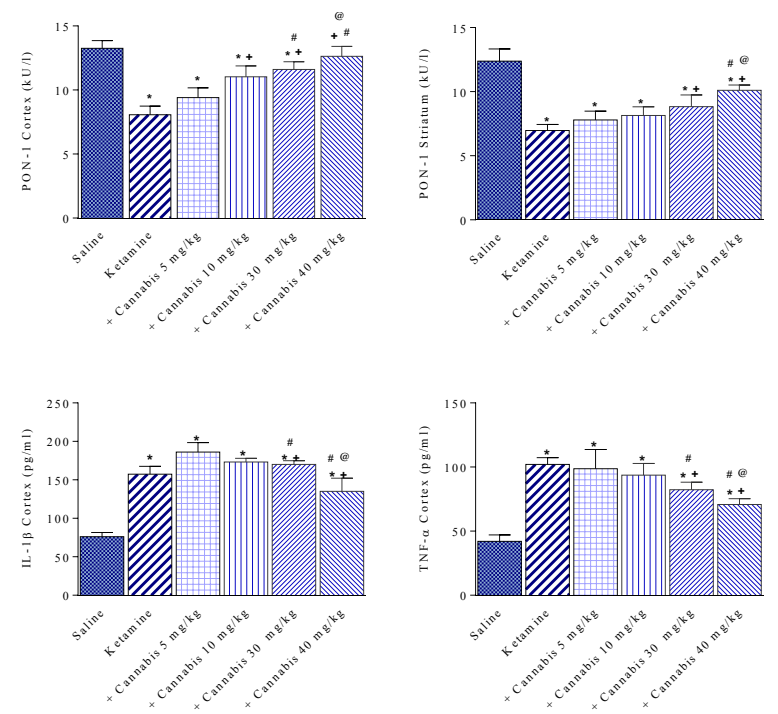
Fig. 2. Paraoxonase-1 (PON-1), interleukin-1 $\beta$ (IL-1 $\beta)$ and tumour necrosis factor- $\alpha(\mathrm{TNF}-\alpha)$ in the rat brain after treatment with saline, ketamine or cannabis/ ketamine. Rats received s.c. injections of cannabis extract $(10,20,30$ or $40 \mathrm{mg} / \mathrm{kg}$; expressed as $\Delta^{9}$-THC content) daily for three weeks and then in combination with ketamine $(15 \mathrm{mg} / \mathrm{kg}$, i.p.) for another 5 days. *: $\mathrm{P}<0.05$ vs. saline control. +: $\mathrm{P}<0.05$ vs. ketamine only group. \#: $\mathrm{P}<0.05$ vs. ketamine/cannabis $5 \mathrm{mg} / \mathrm{kg}$ treated group. @: $\mathrm{P}<0.05$ vs. ketamine/cannabis $10 \mathrm{mg} / \mathrm{kg}$ treated group.

\subsection{Histopathological results}

Sections from the control group showed normal histological structure of the cerebral cortex and striatum (Fig. 3A \& 4A). The group treated with ketamine at $15 \mathrm{mg} / \mathrm{kg}$ for 5 days showed numerous histopathological changes including a large number of damaged neurons, degenerated, necrotic and vacuolated cells. Nuclei of the cells were shrunken, pyknotic and congestion of cerebral blood vessel was seen. Also many of damaged astrocytes were in the form of pyknotic, shrunken and vacuolated (Fig. 3B $\& 4 \mathrm{~B})$. In the groups treated with cannabis for 3 weeks prior to ketamine administration, moderately to mild amount of necrosis, vacuolated, pyknotic, apoptotic neurons and mild congestion of cerebral blood vessel were observed in the cortex and striatum, but the mild damage was observed at high doses of cannabis ( $30 \& 40 \mathrm{mg} / \mathrm{kg}$ ) as compared to the group treated with ketamine alone (Fig. 3C-F \& Fig. 4C-F). Cannabis at high doses given prior to ketamine therefore was associated with less damage and only marginally alleviated ketamine -induced neurotoxicity.

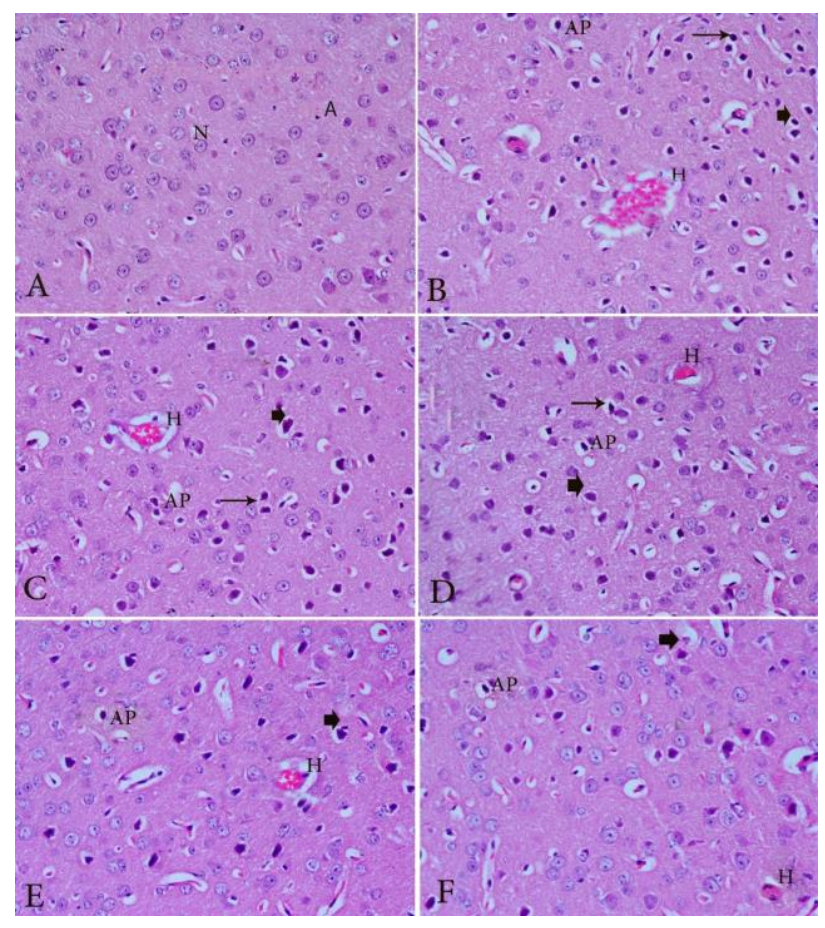

Fig. 3. Representative Hx \& E stained cerebral cortex sections after treatment with: (A) Saline: showing normal histological structure of cortex with normal neurons $(\mathrm{N})$ and astrocytes (A). (B) Ketamine alone showing degenerated, necrosis, vacuolation of the neuronsshrunken, pyknotic (arrowhead), apoptotic nuclei (AP) and congestion of cerebral blood vessel (H) vacuolated and pyknotic astrocytes (thick arrow). (C) Cannabis $5 \mathrm{mg} / \mathrm{kg}+$ ketamine: showing moderate degeneration, necrosis and vacuolation of neurons, shrunken, pyknotic (arrowhead), and apoptotic nuclei (AP) and congestion of cerebral blood vessel (H) as well as vacuolated and pyknotic astrocytes (thick arrow). (D) Cannabis $10 \mathrm{mg} / \mathrm{kg}+$ ketamine: showing moderate degeneration, necrosis and vacuolation of neurons, shrunken, pyknotic (arrowhead), apoptotic nuclei (AP), congestion of cerebral blood vessel (H) and vacuolated and pyknotic astrocytes (thick arrow). (E\&F) Cannabis 30 and $40 \mathrm{mg} / \mathrm{kg}$ + ketamine: showing mild degeneration, necrosis and vacuolation of the neurons, shrunken, pyknotic (arrowhead), apoptotic nuclei (AP) and congestion of cerebral blood vessel $(\mathrm{H})(\mathrm{Hx} \& \mathrm{E} \times 400)$. 


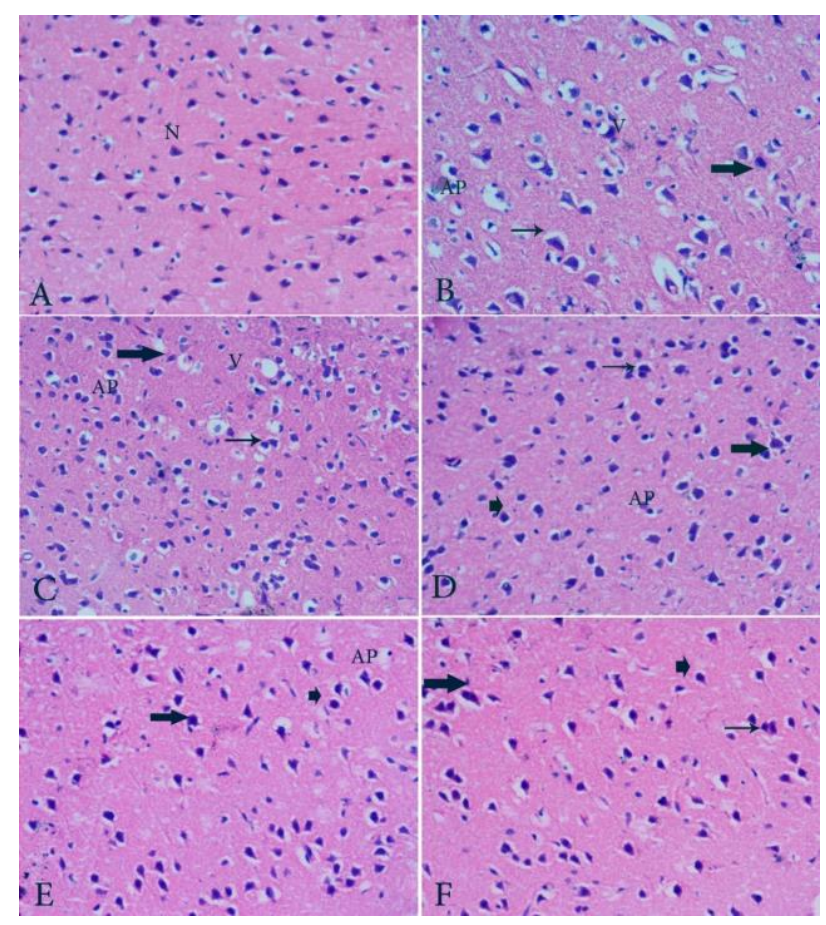

Fig. 4. Representative Hx \& E stained sections of rat striatum after treatment with: (A) Saline: normal histological structure with normal neurons (N). (B) Ketamine alone showing degenerated, necrotic, vacuolated (V) neurons, shrunken, pyknotic nuclei (thin arrow), apoptotic cells (AP) and pyknotic astrocytes (thick arrow). (C \& D) Cannabis 5 \& 10 $\mathrm{mg} / \mathrm{kg}$ + ketamine: showing moderate degeneration, necrosis, vacuolation of neurons (V), shrunken, pyknotic nuclei (thin arrow), associated apoptotic cells (AP) and pyknotic astrocytes (thick arrow). (E \& F) Cannabis 30 and $40 \mathrm{mg} / \mathrm{kg}$ + ketamine: showing mild degeneration, necrosis of neurons, pyknotic nuclei (thin arrow), apoptotic cells (AP) and pyknotic astrocytes (thick arrow) $(\mathrm{Hx} \& \mathrm{E} \times 400)$.

\section{Discussion}

Cannabis sativa and ketamine, two commonly abused substances, have been associated with the development of psychotic events and neurotoxicity. In the current study, we investigated the effect of Cannabis sativa on brain oxidative stress, neuroinflammation and neurodegeneration induced by ketamine injection in the rat. Our results show that ketamine given for 5 consecutive days to rats caused brain oxidative stress. Furthermore, brain levels of IL-1 $\beta$ and TNF- $\alpha$ were upregulated. Ketamine induced neuronal atrophy with loss of prominent axons in cortex and striatum. The prior administration of Cannabis sativa extract for three weeks reduced ketamine-induced oxidative stress, the elevations in IL- $1 \beta$ and TNF- $\alpha$. Moreover, there were reduced neuronal apoptosis and necrosis.
The effect of ketamine on oxidative stress reported herein is also supported by a number of studies. Increased lipid peroxidation and protein carbonyl content in prefrontal cortex was shown after a single dose of ketamine ( $15 \mathrm{or} 25 \mathrm{mg} / \mathrm{kg}$, i.p.) in adult rats [24] and mice [25]. Ketamine given to mice at 30 $\mathrm{mg} / \mathrm{kg}$, i.p., for two consecutive days, was shown to increase IL-6 production, activate NADPH oxidase, increase brain superoxide and cause neuronal injury of a subset of interneurons in prefrontal cortex [26]. There was increased staining for the DNA oxidation marker $8-\mathrm{OHdG}$ in the prefrontal cortex of mice treated with ketamine (30 mg/kg, i.p.) [27]. Increased reactive oxygen species (ROS) formation in mitochondria, reduced mitochondrial membrane potential, mitochondrial swelling and cytochrome c release in mitochondria were observed following ketamine in adult rats $(30 \mathrm{mg} / \mathrm{Kg}$ daily for five consecutive days) [28]. We have also demonstrated increased lipid peroxidation (MDA), and decreased GSH in cerebral cortex and striatum of mice receiving a single dose of ketamine (15 or $30 \mathrm{mg} / \mathrm{kg}$, s.c.) [18]. Oxidative stress therefore is evident in rodent brain after ketamine injection and that make free radical mediated mechanisms an important contributor to the neurodegeneration observed in these animals.

The present study in addition demonstrated a significant inhibition PON1 activity in the brain of ketamine-treated rats which confirms our earlier observations $[18,29]$. The activity of this enzyme which possesses anti-oxidative and antiinflammatory properties decreases in serum of patients with a number of neurological disorders in which free radical- mediated oxidative injury has been implicated in their pathogenesis [30-32]. Increased oxidative stress is found in patients with psychosis [33] and in untreated patients with firstepisode psychosis, serum PON-1 activity is also decreased and this decrease correlated with an increase in proinflammatory cytokines [34]. The enzyme is inactivated by high levels of oxidative stress [35], which could explain a decrease in its activity in neurological disorders as well as in the current study.

We also showed that ketamine increased brain levels of IL- $1 \beta$ and TNF- $\alpha$. A previous study found that a single dose of ketamine (15 or $30 \mathrm{mg} / \mathrm{kg}$, s.c.) increased TNF- $\alpha$ in cortex in both saline and LPStreated rats [18]. Sedky et al. [36] reported increased level of TNF- $\alpha$ in brain of rats by $25 \mathrm{mg} / \mathrm{kg}$ of ketamine (i.p., for one week) while Abelaira et al. 
[24] showed increased TNF- $\alpha$ in serum of rats given a single i.p., dose of $15 \mathrm{mg} / \mathrm{kg}$. Moreover, a study by $\mathrm{Li}$ et al. [37] reported increased levels of IL-1 $\beta$ in rat hippocampus after single and repeated doses of ketamine. TNF- $\alpha$, however, increased after single dose of ketamine but decreased following repeated ketamine injections. These proinflammatory cytokines IL-1 $\beta$ and TNF- $\alpha$ are capable of exacerbating neurodegeneration $[38,39]$ and an increase in their levels could underlie the neuronal injury caused by ketamine. Other studies, however, reported inhibition of proinflammatory cytokines by ketamine both in vitro [40] and in vivo [41]. Thus, ketamine at $10 \mathrm{mg} / \mathrm{kg}$, i.p., for two days was found to decrease the expression of IL- 6 and IL-1 $\beta$ in rat prefrontal cortex and hippocampus [41]. The discrepancies in the effect of ketamine on proinflammatory cytokines are probably caused by different doses and/or the experimental models used.

Consistent with previous reports $[18,29,42,43]$ ketamine induced neuronal injury. Ketamine increased cell death in hippocampal CA3 of adult mice [42]. In neurons from human embryonic stem cells (hESCs) ketamine increased ROS production and cytochrome $\mathrm{c}$ release from mitochondria, induced ultrastructural abnormalities and caused cell death [43]. In humans, cortical atrophy has been reported in chronic users of the drug [44]. The neuropharmacological effects of ketamine are complex. Ketamine effects are mainly attributed to blockade of NMDA glutamate type receptors [45]. Glutamate is the major excitatory neurotransmitter in the CNS [46]. Ketamine has been shown to enhance the release of glutamate in cortex and striatum $[47,48]$, decreases GABA-ergic inhibitory neurotransmission [49] and increases neuronal cortical excitability [48]. It has also been shown that prolonged exposure to the drug increases NMDA receptor expression, resulting in higher/toxic influx of calcium into neurons, increased ROS generation and neuronal cell death [50]. Excitotoxicity and/or free radical-mediated oxidative stress thus might underlie the neurotoxicity of ketamine.

The present study suggests that the pretreatment with Cannabis sativa reduces the ketamine effects on oxidative stress, neuroinflammation and neuronal injury. In fact, these findings were unexpected in view of experimental $[9,10,51,52]$ and human data [8] suggestive of neurodegenerative effect for longterm and heavy cannabis use. Although in this study we did not investigate the effect of cannabis alone, previous studies showed that treatment of rats with Cannabis sativa at doses of 10 or $20 \mathrm{mg} / \mathrm{kg}$ once a day s.c., for 2-6 weeks was associated with dosedependent signs of neurodegeneration in the form of dark and shrunken nuclei, dark apoptotic neurons, focal gliosis as well as increased caspase-3 immunoreactivity $[9,10,53]$. Cannabis also increased neuronal damage in hippocampus and cerebral cortex and caspase-3 immunoreactivity in degenerating neurons of the cortex after LPS injection in mice [53]. Other researchers reported shrinkage of neuronal cell bodies and nuclei besides genomic DNA strand breaks in hippocampal neurons exposed to THC [51]. Cannabis did not reduce nigrostriatal damage in mice treated with rotenone and/or LPS despite lowered levels of oxidative stress [53]. Cannabis given before inducing global cerebral ischaemia, however, conferred protection against the ischaemic neuronal injury [54]. In cerebral ischaemia, there is excessive release of glutamate and over-stimulation of NMDA, AMPA and kinate receptors, resulting in intracellular accumulation of toxic levels of calcium and neuronal death [55]. $\Delta^{9}$-THC or other cannabinoids have been shown to prevented neuronal death in models of glutamate-induced excitotoxic neuronal injury [56,57]. $\Delta^{9}$-THC and cannabinoid receptor agonists act presynaptically to inhibit the release of glutamate, and excitatory synaptic transmission $[58,59]$. Cannabinoids also counteract the toxic effects of glutamate-NMDA on stimulation of the nitric oxide and zinc release [60]. Cannabis and/or $\Delta^{9}-\mathrm{THC}$ by affecting glutamate release and reducing excitotoxicity might thus counteract the effect of ketamine on neuronal integrity. Other mechanisms including inhibition of TNF- $\alpha$, IL- $1 \beta$ and NO release by glia cells, and decreased oxidative stress by cannabis constituents could also be involved.

\section{Conclusion}

In summary, this study showed for the first time that a Cannabis sativa extract rich in $\Delta^{9}$-THC given as a pretreatment to ketamine-treated rats was associated with reduced neuronal damage compared with ketamine only treatment. This might be due to blockade of ketamine effect in the presence of some compounds in the cannabis. Clearly, further studies are needed to delineate the effects of prolonged cannabis use on neurodegeneration and cognitive performances induced by chronic ketamine use.

\section{References:}

[1] Huestis MA. Cannabis (Marijuana) — effects on human behavior and performance. Forensic Science Review 2002; 14:15.

[2] World Drug Report. United Nations Publication, 2020. Sales No. E.20.XI.6. 
[3] Mechoulam R, Gaoni Y. The absolute configuration of delta-1-tetrahydrocannabinol, the major active constituent of hashish. Tetrahedron Letters 1967; 12: 1109-1111.

[4] Pellati F, Borgonetti V, Brighenti V, Biagi M, Benvenuti S, Corsi L. Cannabis sativa L. and nonpsychoactive cannabinoids: their chemistry and role against oxidative stress, inflammation, and cancer. Biomed Research International 2018; 2018:1691428.

[5] Lu HC, Mackie K. An introduction to the endogenous cannabinoid system. Biological Psychiatry 2016; 79:516-525.

[6] Elsohly MA, Slade D. Chemical constituents of marijuana: the complex mixture of natural cannabinoids. Life Sciences 2005; 78: 539-548.

[7] Murray RM, Englund A, Abi-Dargham A, Lewis DA, Di Forti M, Davies C, Sherif M, McGuire P, D'Souza DC. Cannabis-associated psychosis: Neural substrate and clinical impact. Neuropharmacology 2017; 124: 89-104.

[8] Burggren AC, Shirazi A, Ginder N, London ED. Cannabis effects on brain structure, function, and cognition: considerations for medical uses of cannabis and its derivatives. American Journal of Drug and Alcohol Abuse 2019; 45:563-579.

[9] Abdel-Salam, O.M.E., Nada, S.A., Salem, N.A., El-Shamarka, M.E.-S., Omara, E. Effect of Cannabis sativa on oxidative stress and organ damage after systemic endotoxin administration in mice. Comparative Clinical Pathology 2014; 23: 1069-1085.

[10] Abdel-Salam OME, Youness ER, Shaffee N. Biochemical, immunological, DNA and histopathological changes caused by Cannabis Sativa in the rat. Journal of Neurology and Epidemiology 2014; 2: 6-16.

[11] Mion G, Villevieille T. Ketamine pharmacology: an update (pharmacodynamics and molecular aspects, recent findings). CNS Neuroscience \& Therapeutics 2013; 19: 370 380.

[12] Niesters M, Martini C, Dahan A. Ketamine for chronic pain: risksand benefits. British Journal of Clinical Pharmacology 2014; 77:357-367.

[13] Ahern TL, Herring AA, Anderson ES, Madia VA, Fahimi J, Frazee BW. The first 500: initial experience with widespread use of lowdoseketamine for acute pain management in the ED. American Journal of Emergency Medicine 2015; 33:197-201.

[14] Beaudoin FL, Lin C, Guan W, Merchant RC. Low-dose ketamine improves pain relief in patients receiving intravenous opioids for acute pain in the emergency department: results of a randomized, double-blind, clinical trial. Academic Emergency Medicine 2014; 21:11931202.

[15] Lim DK. Ketamine associated psychedelic effects and dependence. Singapore Medical Journal 2003; 44:031-034.

[16] Becker A, Grecksch G. Ketamine-induced changes in rat behaviour: a possible animal model of schizophrenia. Test of predictive validity. Progress in NeuroPsychopharmacology \& Biological Psychiatry 2004; 28:1267-1277,

[17] Liu F, Paule MG, Ali S, Wang C. Ketamineinduced neurotoxicity and changes in gene expression in the developing rat brain. Current Neuropharmacology 2011;9(1):256-61.

[18] Abdel-Salam OME, Youness ER, Mohammed NA, Omara EA, Sleem AA. Effect of ketamine on oxidative stress following lipopolysaccharide administration. Comparative Clinical Pathology $2015 ; 24: 53-63$.

[19] Turner JC, Mahlberg PG. Separation of acid and neutral cannabinoidsin Cannabis sativa L. using HPLC. In: Agurell S, Dewey WL, Willete RE (eds), Chemical, Pharmacological and Therapeutic Agents. Academic, London, 1984. p 79-88.

[20] Nair V, Turner GA. The thiobarbituric acid test for lipid peroxidation: structure of the adduct with malondialdehyde. Lipids 1984; 19:804-5.

[21] Ellman GL. Tissue sulfhydryl groups. Archives of Biochemistry and Biophysics 1959; 82:70-7.

[22] Miranda KM, Espey MG, Wink DA. A rapid, simple spectrophotometric method for simultaneous detection of nitrate and nitrite. Nitric Oxide 2001; 5:62-71.

[23] Haagen L, Brock A. A new automated method for phenotyping arylesterase (EC 3.1.1.2) based upon inhibition of enzymatic hydrolysis of 4nitrophenyl acetate by phenyl acetate. European Journal Of Clinical Chemistry And Clinical Biochemistry 1992; 30:391-5.

[24] Abelaira HM, Réus GZ, Ignácio ZM, Dos Santos MAB, de Moura AB, Matos D et al.. Ketamine exhibits different neuroanatomical profile after mammalian target of rapamycin inhibition in the prefrontal cortex: the role of inflammation and oxidative stress. Cellular and Molecular Neurobiology 2017; 54:5335-5346,

[25] da Silva FC, do Carmo de Oliveira Cito M, da Silva MI, Moura BA, de Aquino Neto MR, Feitosa ML et al. Behavioral alterations and prooxidant effect of a single ketamine administration to mice. Brain Research Bulletin 2010; 83:9-15. 
[26] Behrens MM, Ali SS, Dugan LL. Interleukin-6 mediates the increase in NADPH-oxidase in the ketamine model of schizophrenia. Journal of Neuroscience 2008; 28:13957-13966.

[27] Sorce S, Schiavone S, Tucci P, Colaianna M, Jaquet $\mathrm{V}$, Cuomo $\mathrm{V}$ et al. The NADPH oxidase NOX2 controls glutamate release: a novel mechanism involved in psychosis-like ketamine responses. Journal of Neuroscience 2010; 30:11317-25.

[28] Faizi M, Salimi A, Rasoulzadeh M, Naserzadeh P, Pourahmad J. Schizophrenia induces oxidative stress and cytochrome c release in isolated rat brain mitochondria: A possible pathway for induction of apoptosis and neurodegeneration. Iranian Journal of Pharmaceutical Research 2014; 13 (Suppl): 93-100.

[29] Abdel-Salam OME, El-Shamarka M E-S. Nicorandil reverses the behavioral changes and brain oxidative stress in a model of schizophrenia induced by ketamine in mice. Comparative Clinical Pathology 2017; 26:955-963.

[30] Jamroz-Wisniewska A, Beltowski J, Stelmasiak $\mathrm{Z}$, Bartosik-Psujek H. Paraoxonase 1 activity in different types of multiple sclerosis. Multiple Sclerosis Journal 2009; 15:399-402.

[31] Abdel-Salam OME, Youness ER, Mohammed NA, Abu Elhamed WA. Nuclear factor-kappa B and other oxidative stress biomarkers in serumof autistic children. Open Journal of Molecular and Integrative Physiology 2015; 5:18 27.

[32] Castellazzi M, Trentini A, Romani A, Valacchi G, Bellini $T$, Bonaccorsi $G$, et al. Decreased arylesterase activity of paraoxonase-1 (PON-1) might be a common denominator of neuroinflammatory and neurodegenerative diseases. The International Journal of Biochemistry \& Cell Biology 2016; 81:356-63.

[33] Lee EE, Eyler LT, Wolkowitz OM, Martin AS, Reuter C, Kraemer H et al. Elevated plasma F2isoprostane levels in schizophrenia Schizophrenia Research 2016; 176:320-326.

[34] Brinholi FF, Noto C, Maes M, Bonifácio KL, Brietzke E, Ota VK et al. Lowered paraoxonase 1 (PON1) activity is associated with increased cytokine levels in drug naïve first episode psychosis. Schizophrenia Research 2015; 166:225-230.

[35] Nguyen SD, Sok DE. Preferential inhibition of paraoxonase activity of human paraoxonase 1 by negatively charged lipids. Journal of Lipid Research 2004; 45:2211-20.

[36] Sedky AA, Magdy Y. Reduction in TNF alpha and oxidative stress by liraglutide: Impact on ketamine-induced cognitive dysfunction and hyperlocomotion in rats. Life Sciences 2021:119523.

[37] Li Y, Shen R, Wen G, Ding R, Du A, Zhou J et al. Effects of ketamine on levels of inflammatory cytokines IL-6, IL-1 $\beta$, and TNF- $\alpha$ in the hippocampus of mice following acute or chronic administration. Frontiers in Pharmacology 2017; 8:139.

[38] Pott Godoy MC, Tarelli R, Ferrari CC, Sarchi MI, Pitossi FJ. Central and systemic IL-1 exacerbates neurodegeneration and motor symptoms in a model of Parkinson's disease. Brain 2008 ;131:1880-94.

[39] Koprich JB, Reske-Nielsen C, Mithal P, Isacson O. Neuroinflammation mediated by IL-1beta increases susceptibility of dopamine neurons to degeneration in an animal model of Parkinson's disease. Journal of Neuroinflammation 2008;5:8.

[40] Lankveld DP, Bull S, Van Dijk P, FinkGremmels J, Hellebrekers LJ. Ketamine inhibits LPS-induced tumour necrosis factor-alpha and interleukin-6 in an equine macrophage cell line. Veterinary Research 2005;36(2):257-62.

[41] Yang C, Hong T, Shen J, Ding J, Dai XW, Zhou $Z Q$ et al. Ketamine exerts antidepressant effects and reduces IL-1 $\beta$ and IL-6 levels in rat prefrontal cortex and hippocampus. Experimental and Therapeutic Medicine 2013; 5:1093-1096.

[42] Majewski-Tiedeken CR, Rabin CR, Siegel SJ. Ketamine exposure in adult mice leads to increased cell death in $\mathrm{C} 3 \mathrm{H}, \mathrm{DBA} 2$ and FVB inbred mouse strains. Drug and Alcohol Dependence 2008; 92: 217-227.

[43] Bosnjak ZJ, Yan Y, Canfield S, Muravyeva MY, Kikuchi C, Wells CW et al. Ketamine induces toxicity in human neurons differentiated from embryonic stem cells via mitochondrial apoptosis pathway. Current Drug Safety 2012; 7:106-19.

[44] Wang C, Zheng D, Xu J, Lam W, Yew DT. Brain damages in ketamine addicts as revealed by magnetic resonance imaging. Frontiers in Neuroanatomy 2013; 7:23.

[45] Kurdi MS, Theerth KA, Deva RS. Ketamine: Current applications in anesthesia, pain, and critical care. Anesthesia: Essays and Researches 2014; 8: 283-290.

[46] Meldrum BS. Glutamate as a neurotransmitter in the brain: review of physiology and pathology. Journal of Nutrition 2000; 130: 1007S-1015S.

[47] Lisek M, Ferenc B, Studzian M, Pulaski L, Guo $\mathrm{F}$, Zylinska L et al. Glutamate Deregulation in Ketamine-Induced Psychosis-A Potential Role of PSD95, NMDA Receptor and PMCA 
Interaction. Frontiers in Cellular Neuroscience 2017; $11: 181$.

[48] Di Lazzaro V, Oliviero A, Profice P, Pennisi MA, Pilato F, Zito G et al. Ketamine increases human motor cortex excitability to transcranial magnetic stimulation. The Journal of Physiology 2003; 547:485-96.

[49] Weckmann K, Deery MJ, Howard JA, Feret R, Asara JM, Dethloff F et al. Ketamine's effects on the glutamatergic and gabaergic systems: A proteomics and metabolomics study in mice. Molecular Neuropsychiatry 2019;5: 42-51.

[50] Liu F, Patterson TA, Sadovova N, Zhang X, Liu $\mathrm{S}$, Zou X et al. Ketamine-induced neuronal damage and altered N-methyl-D-aspartate receptor function in rat primary forebrain culture. Toxicological Sciences 2013; 131:548-57.

[51] Chan GC, Hinds TR, Impey S, Storm DR. Hippocampal neurotoxicity of Delta 9tetrahydrocannabinol. Journal of Neuroscience 1998; 18: 5322-32.

[52] Wolff V, Schlagowski AI, Rouyer O, Charles $\mathrm{AL}$, Singh F, Auger $\mathrm{C}$ et al. Tetrahydrocannabinol induces brain mitochondrial respiratory chain dysfunction and increases oxidative stress: a potential mechanism involved in cannabis-related stroke. BioMed Research International 2015; 2015:323706.

[53] Abdel-Salam OME, Omara EA, El-Shamarka ME-S., Hussein JS. Nigrostriatal damage after systemic rotenone and/or lipopolysaccharide and the effect of cannabis. Comparative Clinical Pathology 2014; 23: 1343-1358.

[54] Abdel-Salam OME, Abdel Jaleel G, Morsy FA. Acute effects of Cannabis sativa on ischaemia/reperfusion injury in the rat brain. Journal of Neurology and Epidemiology 2017; 5: 25-34.

[55] Choi DW, Koh JY, Peters S. Pharmacology of glutamate neurotoxicity in cortical cell culture: attenuation by NMDA antagonists. Journal of Neuroscience 1988; 8:185-96.

[56] van der Stelt M, Veldhuis WB, Bär PR, Veldink GA, Vliegenthart JF, Nicolay K. Neuroprotection by Delta9tetrahydrocannabinol, the main active compound in marijuana, against ouabain-induced in vivo excitotoxicity. Journal of Neuroscience 2001;21: 6475-9.

[57] Moldzio R, Krewenka C, Radad K, Duvigneau JC, Miller I, Huu CN. THC exerts neuroprotective effect in glutamate affected murine primary mesencephalic cultures and neuroblastoma N18TG2 cells. Planta Medica 2015; 81 - PW_130.
[58] Gerdeman G, Lovinger DM. CB1 cannabinoid receptor inhibits synaptic release of glutamate in rat dorsolateral striatum. Journal of Neurophysiology 2001; 85:468-471.

[59] Colizzi M, McGuire P, Pertwee RG, Bhattacharyya S. Effect of cannabis on glutamate signalling in the brain: A systematic review of human and animal evidence. Neuroscience \& Biobehavioral Reviews 2016; 64:359-81.

[60] Sánchez-Blázquez $P$, Rodríguez-Muñoz $M$, Vicente-Sánchez A, Garzón J. Cannabinoid receptors couple to NMDA receptors to reduce the production of $\mathrm{NO}$ and the mobilization of zinc induced by glutamate. Antioxidants \& Redox Signaling 2013; 19:1766-82.

Competing interests:

No competing interests to disclose.

Author Contributions:

All authors contributed equally to the manuscript, read and approved the final version.

Source of funding:

This work was supported by NRC research grant No S90503.

\section{Creative Commons Attribution}

\section{License 4.0 (Attribution 4.0 International , CC BY 4.0)}

This article is published under the terms of the Creative Commons Attribution License 4.0 https://creativecommons.org/licenses/by/4.0/dee d.en US 